\title{
On- and Off-Farm Diversification and Travel Time to Markets: Linkages to Food Security in Rural Ethiopia
}

\author{
Sven Bergau ${ }^{1} \cdot \operatorname{Tim}_{\mathrm{K}}$. Loos $^{2} \cdot$ Orkhan Sariyev $^{1}$ (1)
}

Accepted: 23 September 2021 / Published online: 7 October 2021

(c) The Author(s) 2021

\begin{abstract}
Food insecurity persists in large parts of Ethiopia. Recent literature suggests that both on-farm and off-farm diversification, as well as access to agricultural markets, may help improve household dietary diversity scores (HDDS) as an indicator for food and nutrition security. While the HDDS is frequently used, a diversity score for the production side has rarely been applied at a comparable level of (dis-)aggregation. Employing socio-economic data collected covering 400 Ethiopian smallholder farmers, this study investigates how the travel time to markets, non-farm income, and on-farm production diversity associate with household food and nutrition security. Findings suggest that production diversity and higher non-farm income are linked to more diverse diets. With longer travel time to markets, food consumption is less varied. Production diversity and increased market participation do not appear to be mutually exclusive, and thus, should be considered equally when developing policy interventions.
\end{abstract}

Keywords Income diversification · Production diversity · Market access · Dietary diversity $\cdot$ Ethiopia

\section{Resume}

L'insécurité alimentaire reste prévalente dans une grande partie de l'Éthiopie. La littérature récente suggère que la diversification à la ferme et hors ferme, ainsi que l'accès aux marchés agricoles, peuvent aider à améliorer les scores de diversité ali-

Orkhan Sariyev

o.sariyev@uni-hohenheim.de

Sven Bergau

s.bergau@posteo.de

Tim K. Loos

tim.loos@giz.de

1 Hans-Ruthenberg-Institute, University of Hohenheim, Wollgrasweg 43, 70599 Stuttgart,

Germany

2 Deutsche Gesellschaft für Internationale Zusammenarbeit (GIZ) GmbH, Friedrich-Ebert-Allee 13, 53113 Bonn, Germany 
mentaire des ménages (SDAM) en tant qu'indicateur de la sécurité alimentaire et nutritionnelle. Alors que le SDAM est fréquemment utilisé, un score de diversité du côté de la production a rarement été appliqué à un niveau comparable de (dés)agrégation. En utilisant des données socio-économiques collectées auprès de 400 petits agriculteurs éthiopiens, cette étude examine la façon dont le temps de trajet vers les marchés, les revenus non agricoles et la diversité de la production à la ferme sont associés à la sécurité alimentaire et nutritionnelle des ménages. Les résultats suggèrent que la diversité de la production et des revenus non agricoles plus élevés sont liés à des régimes alimentaires plus diversifiés. Avec un temps de trajet plus long vers les marchés, la consommation alimentaire est moins variée. Une production diversifiée et une participation accrue aux marchés ne semblent pas s'exclure mutuellement et devraient donc être considérées de la même manière lors de l'élaboration des politiques publiques.

\section{Introduction}

Sufficient and adequate food and nutrition are crucial to individuals' wellbeing and any nation's economic development (World Food Programme 2014). Past experience and present developments have clearly proven that the consequences of food and nutrition insecurity are massive and pervasive (Gillespie and van den Bold 2017). A particularly vulnerable group are smallholder farming households, especially in developing countries (Barrett 2010; Mullerr 2009). Often, their provision of food is obtained directly through subsistence agriculture and indirectly through sales of agricultural products. Either way, their food supply is largely dependent on agricultural production characterized by small-scale, low-mechanized, and often lowincome farming practices. In addition, financial and social assets are often relatively low, driving up the susceptibility and consequences in case of natural or marketborne fluctuations (Berhane et al. 2013).

In Ethiopia, most of the population lives in remote areas, engages in smallholder agriculture and faces the threat of multidimensional poverty (World Bank 2016). With the support of productivity increases from strategies like Agricultural Development Led Industrialization (ADLI), the country has shown internationally acclaimed economic development over recent decades (FAO 2014; World Bank 2016). However, Ethiopia is still prone to food and nutrition insecurity, especially during the irregular droughts that are worsened by climate change (UNDP 2016).

Regarding pathways to enhance food and nutrition security of vulnerable smallholder farmers, findings in recent literature recommend both on-farm and income diversification, as well as improved access to agricultural markets (Koppmair et al. 2017; Otsuka and Yamano, 2016; Sibhatu et al. 2015). Of key concern in this research is the estimation of the influence and importance of these aspects on household dietary diversity scores (HDDS) as an indicator capturing the nutritional component of food security.

In terms of on-farm diversification, it is surprising that the level of (dis-)aggregation is usually at a different level, that is, a simple count of different crop and livestock species or a dummy variable indicating diversified production of some level. 
This may have led to a misinterpretation of the influence of production diversity on dietary diversity (Berti 2015). An aggregation into food groups comparable to that of the dietary diversity score is needed to account for this issue and to enhance the accuracy and expressiveness of production diversity.

Assessing the role of non-farm income in the dietary diversity literature is usually limited to capturing it as a dummy variable (Sibhatu et al. 2015). Additional income sources besides agriculture may provide consistent livelihoods through increased income generation, especially during times of crisis. In such cases, the magnitude of non-farm income appears more relevant than the number of non-farm income sources (de Janvry et al. 1991; Kinsey et al. 1998).

Another important factor influencing household dietary diversity is market access (Koppmair et al. 2017). Market distance has been used in recent literature as a proxy for the infrastructural aspect of market access (e.g., Sibhatu and Qaim 2018a). Smallholder rural farmers are rarely motorized and hence go to markets by foot. Therefore, it seems more appropriate to consider travel time rather than distance. Especially during peak workload phases like the harvest period, time is often the most constraining factor. Moreover, the degree of market participation, that is, the orientation toward sales or subsistence, has so far been rather neglected in the literature, and especially for Ethiopia.

This study considers the above-mentioned methodological shortcomings in the dietary diversity literature and seeks to identify the linkages between dietary diversity and on- and off-farm diversification and market access.

Following this introduction, a review of the current literature provides an overview and indicates which factors influence dietary diversity. Then, the study area and dataset are introduced and the statistical methods are explained. After describing and discussing the results, concluding remarks and acknowledgment of the study's limitations are provided.

\section{Data and Methods}

\section{Data}

The cross-sectional data analyzed in this study were collected in 2016 in the context of a panel study on technology adoption. The nationally representative baseline survey was conducted by the International Food Policy Institute (IFPRI) for the Agricultural Transformation Agency (ATA) in 2012. Due to logistical limitations, a subsample of the baseline was drawn covering all originally sampled households living within a 150-200 km radius around Hawassa (about $270 \mathrm{~km}$ south of Addis Ababa). This geographic localization covers diverse production systems in a wide range of agroclimatic zones in the Oromia and SNNP regions.

By means of computer-assisted personal interviews (CAPI), experienced and well-trained enumerators interviewed farming households, collecting information on a wide array of topics to include agricultural production and non-farm income, household food consumption, agricultural technology adoption, agricultural markets, institutions, and services. Households that did not engage in cropping activities 
were excluded, bringing the total sample size to 400. All relevant variables for the econometric analyses were selected based on their importance as identified in the literature review.

\section{Measuring Food and Nutrition Security}

Food security is a key aspect for humans and considered a basic human right. It is a necessary condition to develop mental and physical health, and thus it is crucial to ensure economic productivity and, on a large scale, political stability (Gillespie and van den Bold 2017). Most commonly, four dimensions of food security are defined: (i) food availability, (ii) economic and physical access to food, (iii) food utilization, and (iv) stability (vulnerability and shocks) over time. Capturing all four aspects in analyses is rather cumbersome. Therefore, researchers most often decide on analyzing dietary diversity as an indicator. Headey and Ecker (2013) show that dietary diversity indicators are useful for reflecting nutritional aspects of food security. Intake of diverse food items is regarded as an important component of food security, because it has consistently been associated with increased energy and more adequate nutrient intake, as well as increased anthropometric outcomes (Hatløy et al. 1998; Kant 2004; Rose et al. 2002; Ruel 2003; Tarini et al. 1999; Torheim et al. 2004). Similarly, low dietary diversity levels are correlated with micronutrient deficiencies, stunting of children, child deaths and several other negative health outcomes (Koppmair et al. 2017). A widely chosen indicator is the household dietary diversity score (HDDS) a tool to help establish the prevalence of dietary diversity at the household level (Hirvonen and Hoddinott 2014; Hirvonen et al. 2015; Jones et al. 2013, 2014; Sariyev et al. 2021; Sibhatu et al. 2015; Sibhatu and Qaim 2018a; Snapp and Fisher 2014). Many national and regional statistics and datasets deliver the relevant information at a household level, and new data collection is straightforward and relatively cheap, making this a valid and often used option in food and nutrition security research. The HDDS is usually calculated using 12 food groups (Kennedy et al. 2010), and is sometimes (as in this study) compared with an HDDS using nine food groups, which excludes oils and fats, sweets, and spices, condiments, and beverages. The HDDS used in this study is based on a seven-day recall period.

\section{Determining Factors of Dietary Diversity}

In the case of predominantly subsistence farming, the link between agriculture and food and nutrition security seems apparent. A more diverse range of cultivated crops or livestock species can be expected to increase household dietary diversity (Jones et al. 2014). A meta-analysis by Sibhatu and Qaim (2018b) discusses this hypothesized and frequently observed positive association. They conclude that on-farm diversification is not a very effective strategy, because increasing diet diversity by one food group will require a substantial increase in farming activities (nine to 16 additional species). High diversification levels might also prevent households from specializing and focusing on specific products. Moreover, income must be generated to purchase food and additional items that household cannot directly produce. 
Missing out on these advantages could lead to potential income losses and therefore negative dietary diversity outcomes (Sibhatu et al. 2015).

On the other hand, production diversification may accompany the implementation of agricultural technologies like agroforestry or intercropping practices. In such cases, there would not only be the diversification aspect, but also additional benefits like a positive effect on soil conservation, improved water use, suppressed weeds, and better pest control (Szumigalski and van Acker 2005; Zöbisch et al. 1995). In this respect, agricultural innovations may also help stabilize or enhance yields and improve the produce available for home consumption or sale, thus enhancing dietary diversity. Furthermore, input-based technologies like improved seed or chemical fertilizers were found to have positive social, economic and food security related outcomes due to increased income (Bachewe et al. 2015; Koppmair et al. 2017; Emana et al. 2010). Although adopting suitable technologies fosters dietary diversity, different studies emphasize the role of extension services and education in general for improving dietary diversity (Stifel and Minten 2017; Minten et al. 2013; Berhane et al. 2013).

While on-farm diversification may increase consumption diversity directly, the other factors' effects are rather indirect. Increased surplus can be sold on the market and the income generated from market participation may then be used to purchase other food items. Recent literature on the role of market access and market participation reports positive effects on HDDS in various African countries (Bellon et al. 2016; Hirvonen and Hoddinott 2014; Koppmair et al. 2017; Sibathu et al. 2015; Sibathu and Qaim 2018a). Another strategy to generate income is involving in nonfarm activities. Otsuka and Yamano (2006) underline the relevance of income diversity practices outside agriculture for enhanced poverty reduction. Several studies additionally emphasize a strong positive relationship between non-farm income and household welfare indicators, as well as off-farm income diversification and growth in income and consumption (Barrett et al. 2001; Reardon et al. 1994).

Figure 1 summarizes which factors are expected to affect household dietary diversity, and are thus relevant for analysis. The key independent variables of interest in this study (on-farm production diversity, non-farm income, market access, and agricultural technologies) are described in more detail in the econometric model specification.

\section{Econometric Model Specification and Tests}

\section{Main Variables of Interest}

The main outcome variable of interest is the household dietary diversity score (HDDS). Two variations were calculated based on a seven-day recall of household food consumption: a score using 12 food groups (see Kennedy et al. 2010) and a score using nine food groups $\left(\mathrm{HDDS}_{9}\right)$, which excludes oils and fats, sweets, and spices, condiments, and beverages. On the one hand these food groups might only marginally contribute to the micronutrient density of the diet (Sibhatu et al. 2015), on the other hand, they cannot be easily produced by farmers themselves, meaning 


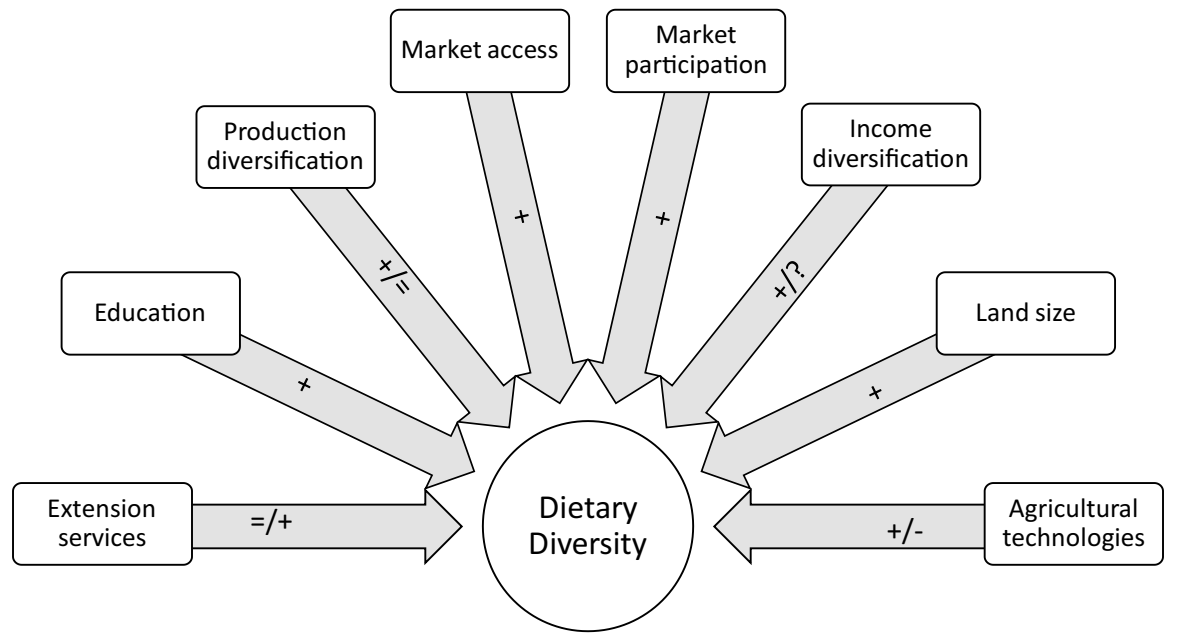

Fig. 1 Factors influencing dietary diversity

that they must almost always be purchased. The main independent variables of interest are the household production diversity score that corresponds to nine food groups (HPDS9) that can actually be produced by households, the ratio of non-farm income to total household income generated from agricultural activities, and the travel time to the nearest periodic agricultural (food) markets.

The household production diversity score (HPDS9) is calculated similarly to the $H D D S$ in order to make them comparable. This means that in contrast to the general trend in the literature of calculating production diversity as a simple count of different crops and animal species, produced food items were aggregated into the same groups as consumed food items. For example, in terms of nutritional value, it is rather redundant to grow wheat and barley, so they were grouped together.

Non-farm income is defined here as income from non-agricultural labor, and therefore, it excludes income generated from work on other farms. This type of income is usually well remembered by the households. We gather information regarding the members' employment status and activities in the household roster. The questionnaire had a section on other income activities where we identified the activities, participating members, and generated income. This information is then cross-checked with the information from household roster. Total household income is calculated as the sum of the gross profit from animal and crop production and all income from other activities, including agricultural wage labor. In the regression analyses, non-farm income is used to reflect the relevance of non-agricultural income in relation to a household's total income.

To properly reflect the effort a household needs to invest to access markets, the travel time to the nearest (periodic) market was chosen. Considering a time aspect contrasts with the commonly used distance or dummy variable, yet seems more reasonable for such cases where almost all households spend a large amount of time walking to the market, implying substantial transaction costs. 
This study is embedded in a technology adoption project; thus, the questionnaire included detailed questions on different agricultural technologies. We control for management and input-based technologies in the regression analyses. Managementbased technologies (MBT) like crop rotation and intercropping/agroforestry can be linked to both on- and off-farm diversification and may influence dietary diversity rather directly. It further included input-based technologies (IBT) like fertilizer and hybrid seeds, which can be linked to higher levels of marketable output and income. In addition, other household socio-economic characteristics were incorporated as control variables.

\section{Model Choice and Statistical Tests}

Measuring dietary diversity with the $H D D S$ results in a count variable with nonnegative integer values between 0 and 12, or between 0 and 9 when focusing on the healthier food groups in the HDDS9. Those healthier food groups also reflect those products that can actually be directly produced by farmers themselves. The observed data closely follows a Poisson distribution. Thus, similar to other studies investigating the HDDS as the dependent variable (Kirvonen and Hoddinott 2014; Koppmair et al. 2017; Sibhatu et al. 2015), Poisson models were considered for the econometric analyses.

By definition, a Poisson model assumes equidispersion, that is, equality of the conditional mean and the conditional variance, reflecting the principle of randomness (Consul and Jain 1973; Greene 2012). However, this idealized assumption is neither natural nor practical in its application (Consul 1989). When applied, dependent variables of count data are often confronted with overdispersion, occurring if the conditional variance exceeds the conditional mean, and sometimes underdispersion, if the conditional variance is smaller than the conditional mean (Greene 2012; Harris et al. 2012). A violation of the equidispersion assumption has similar effects as heteroscedasticity in a linear regression model (Winkelmann and Zimmermann 1994). In the case of an overdispersion the estimated standard errors are biased downwards, while they show an upward bias when the model is underdispersed. The Poisson model was therefore adapted to this problem and its applications and possible uses described by Consul and Jain (1973) in the generalized Poisson model. Following Harris et al. (2012) equidispersion was tested with a likelihood-ratio test and a Pearson $\mathrm{Chi}^{2}$ test, which revealed that the observed HDDS in the dataset is overdispersed (see Table 2). Therefore, the generalized Poisson model was used in the analyses. The log-likelihood function of the Generalized Poisson model is maximized via the maximum-likelihood estimation (MLE) method. The model is tested for statistical significance with the Wald-Chi ${ }^{2}$ test.

The models were calculated with cluster-corrected standard errors. This technique controls for potential error term correlations within Kebeles (Ethiopian administrative units comparable to villages) that could result from environmental conditions or other local influences. In addition, due to the selection of the model from non-experimental data and further sub-selection of covariates rationalized by the authors, multicollinearity between the regression estimates cannot be excluded per se, even if there is no logical expectation upfront (Greene 2012). To control for 
this potential problem that might influence the results and the subsequent interpretation, a variance inflation factor (VIF) test was conducted. The scientific community is still disputing cutoff-values, but as a rule of thumb a VIF below 30 is acceptable (Greene 2012; O’Brien 2007).

Equation 1 depicts the general form of the estimated generalized Poisson model of dietary diversity:

$$
H D D S=\beta_{0}+\beta_{1} H P D S 9+\beta_{2} H P D S+\beta_{3} M+\beta_{4} O+\beta_{5} T A+\beta_{6} X
$$

where HPDS9 household production diversity score of nine food groups, $M$ travel time to agricultural market (minutes), $O$ ratio of non-farm income to total household income (i.e. profit), TA dummy for technology use (e.g., MBTs and IBTs), $X$ vector of socio-economic characteristics (e.g., gender, education, household size, farm size, market orientation etc.)

\section{Sample Description}

Table 1 describes key variables for the underlying household sample. The average household head is a male in his late $40 \mathrm{~s}$, with three years of formal education, and with a family of six members. The high dependency ratio indicates a rather high burden on household members of working age, which may become a constraint in peak labor situations or in the case of illness or injuries. Farming activities are carried out on less than two ha, but often with the support from state or non-governmental extension services. The main source of food and income generation is crop production. In most cases, livestock production and non-farm activities are reported to be additional sources of food and income. Average household is engaged in agricultural production that produces crop or livestock or both that fall into four different food group categories. The household dietary diversity ranges between 3 and 11 food groups with an average of 6.67 .

In terms of cash income, about half (56\%) of the agricultural produce is sold on the market which indicates the importance of both subsistence production and market orientation. With about 50 min walking time (approximately four $\mathrm{km}$ ) to the nearest periodic market, the market distance appears comparably short. Other studies in Ethiopia report market distances of $10.9 \mathrm{~km}$ (Hirvonen and Hoddinott 2014) to $63.53 \mathrm{~km}$ (Sibhatu et al. 2015). Because of this considerable difference, this aspect should be kept in mind when discussing and interpreting results. From the total income generated, $13 \%$ originates from non-farm sources indicating the role of this cash acquisition as ancillary revenue. The main sources of non-farm income are trading/small shops, followed by handicraft, construction work, and other activities. In terms of technologies, about two-thirds (69\%) of the respondents use crop rotation, intercropping, and/or agroforestry practices, thus, the most relevant agricultural technologies appear to be management-based. Hereby, crop rotation is more relevant $(62 \%)$ than intercropping and/or agroforestry (23\%). Input-based technologies are less frequently used. In this sample, $60 \%$ of the households apply pesticides, improved seeds or fertilizer during crop production. Improved seeds and fertilizer 


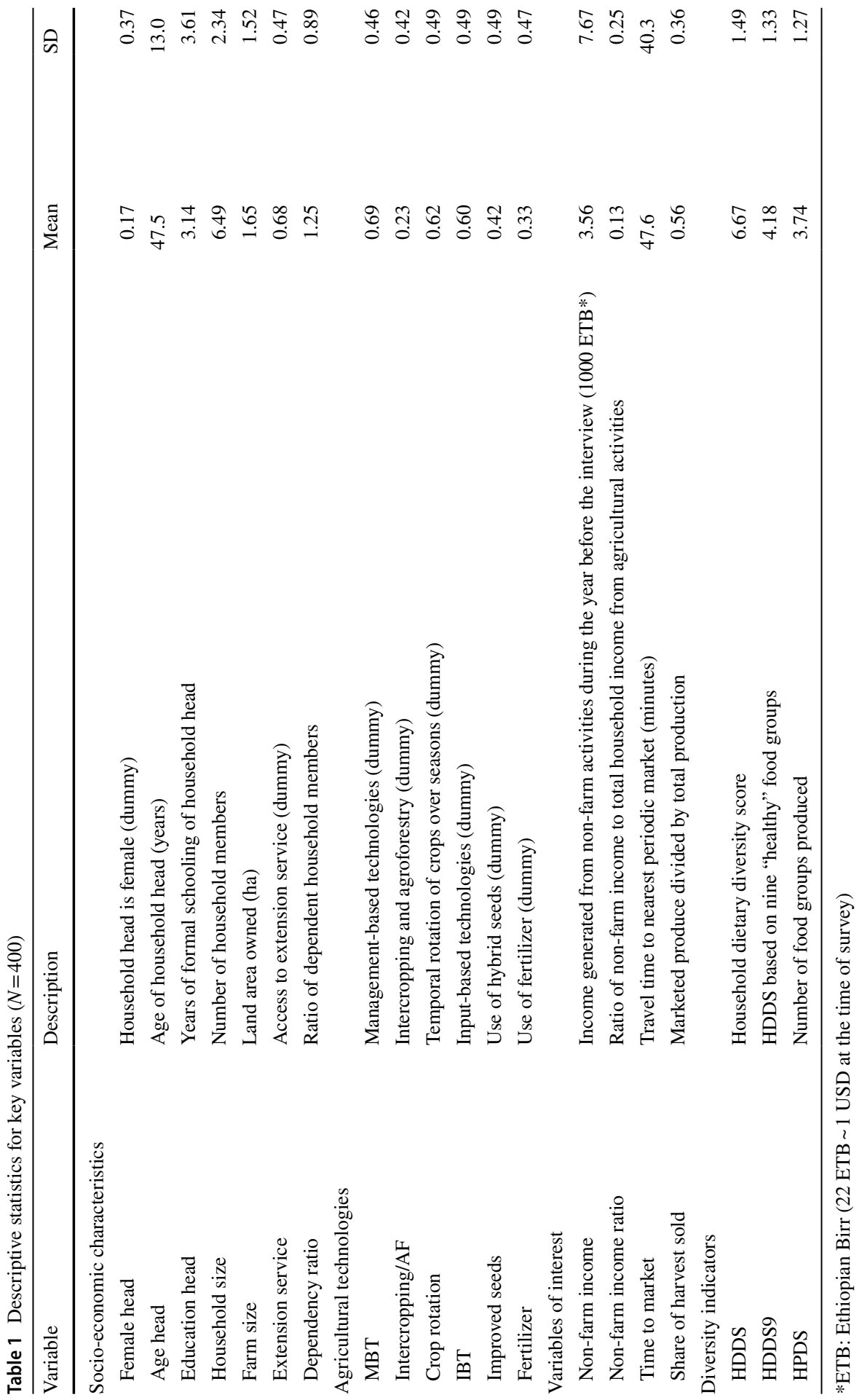


(which were included alongside with pesticides in the input-based technology variable) are used by $42 \%$ and $33 \%$ of the respondents, respectively.

To describe dietary and production diversities in the sampled households, we depict the differences between produced and consumed food groups in Fig. 2. Almost all households consume cereals and vegetables. Traditionally, these are prepared with oil and spices. Other commonly consumed food groups are roots and tubers, legumes, nuts and seeds, as well as milk or milk products. Less commonly consumed are sweets, meat, fruits, and eggs. Fish consumption is negligible in the research area. These consumption patterns are mostly repeated on the production side with the exception of vegetables, which are produced much less than they are consumed. This deviation may be due to seasonality issues or unobserved production choice preferences. Future research could shed more light on this specific case. Somewhat misleading is the food group of meat. Production of this group refers to households keeping livestock. As livestock serves multiple purposes, including milk production and a store of value (i.e., an asset), it can be assumed that the animals are not slaughtered on a regular basis, thus leading to the low consumption, but high meat, or rather animal, production.

\section{Results and Discussion}

This section presents the model estimations and discusses the role of production diversity, non-farm income, and market access for food and nutrition security in rural Ethiopian households. The models displayed in Table 2 show the effect of explanatory variables on the household dietary diversity score of 12 and 9 healthy food groups. To account for structural differences like biophysical properties, cluster-corrected standard errors are reported.

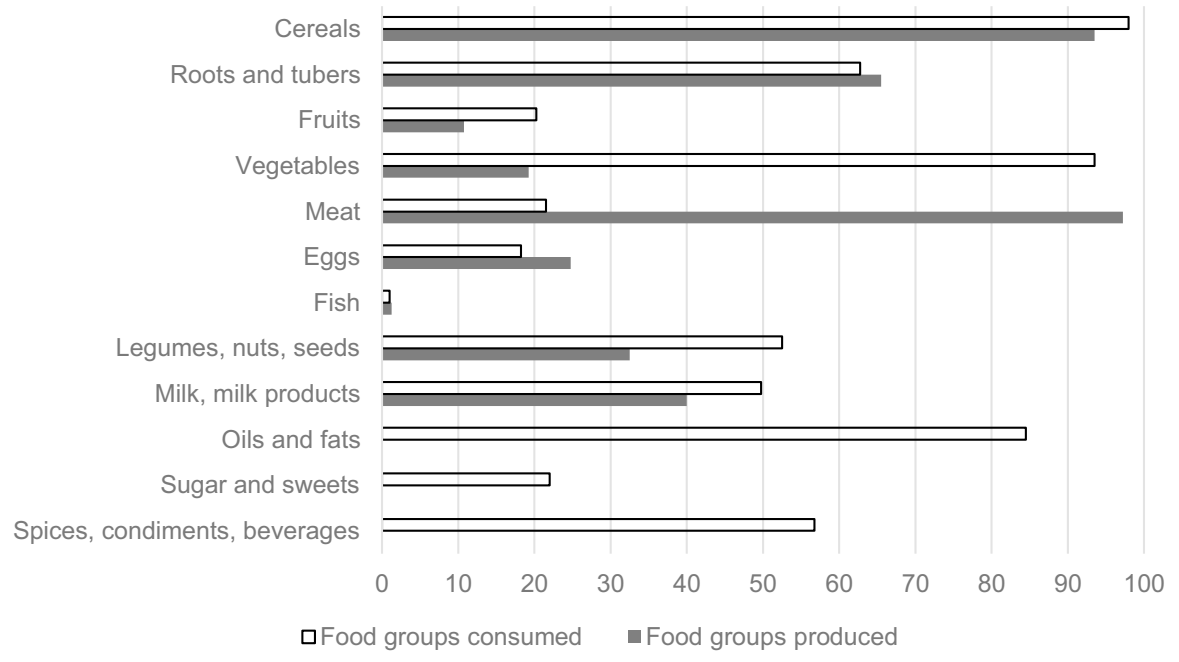

Fig. 2 Share of households producing vs. consuming different food groups 
Table 2 Determining factors of the household dietary diversity score (HDDS)

\begin{tabular}{|c|c|c|c|c|c|c|}
\hline \multirow[t]{2}{*}{ Right-hand side variables } & \multicolumn{3}{|l|}{12 food groups } & \multicolumn{3}{|c|}{9 food groups } \\
\hline & $\begin{array}{l}\text { Right-hand } \\
\text { side variables }\end{array}$ & Sig & s.e $\mathrm{e}^{\mathrm{a}}$ & Coef & Sig & s.e. $^{\mathrm{a}}$ \\
\hline HPDS9 & 0.050 & $* * *$ & $(0.009)$ & 0.074 & $* * *$ & $(0.014)$ \\
\hline Time to market & -0.001 & $* *$ & $(0.000)$ & -0.001 & $*$ & $(0.000)$ \\
\hline Non-farm income ratio & 0.122 & $* * *$ & $(0.042)$ & 0.139 & $* *$ & $(0.057)$ \\
\hline Female household head ${ }^{\mathrm{d}}[1-\mathrm{Yes}]$ & -0.013 & & $(0.029)$ & -0.022 & & $(0.043)$ \\
\hline Years of education for household head & 0.005 & & $(0.003)$ & 0.005 & & $(0.005)$ \\
\hline Age of household head & -0.001 & & $(0.001)$ & -0.001 & & $(0.001)$ \\
\hline Farm size & 0.013 & & $(0.009)$ & 0.008 & & $(0.012)$ \\
\hline Total livestock unit & 0.010 & $* * *$ & $(0.003)$ & 0.014 & $* * *$ & $(0.003)$ \\
\hline Agricultural asset value (1000 ETB) & -0.004 & & $(0.006)$ & -0.001 & & $(0.008)$ \\
\hline Extension access & -0.054 & $* *$ & $(0.022)$ & -0.053 & $*$ & $(0.030)$ \\
\hline Share of harvest sold & 0.063 & $* *$ & $(0.029)$ & 0.089 & $*$ & $(0.049)$ \\
\hline Household size & -0.003 & & $(0.006)$ & 0.000 & & $(0.008)$ \\
\hline Dependency ratio & -0.023 & $*$ & $(0.012)$ & -0.045 & $* * *$ & $(0.016)$ \\
\hline Input-based technologies ${ }^{\mathrm{d}}[1-$ Yes $]$ & 0.042 & $*$ & $(0.023)$ & 0.069 & $* *$ & $(0.031)$ \\
\hline $\begin{array}{l}\text { Management-based technologies }{ }^{\mathrm{d}}[1- \\
\text { Yes] }\end{array}$ & 0.018 & & $(0.020)$ & 0.039 & & $(0.031)$ \\
\hline Wald-Chi ${ }^{2}$ & 280.30 & $* * *$ & & 191.72 & $* * *$ & \\
\hline Delta & -0.95 & $* * *$ & 0.720 & -0.741 & $* * *$ & 0.058 \\
\hline $\mathrm{N}$ & 400 & & & 400 & & \\
\hline
\end{tabular}

$* * *, * *, *$ denote $1 \%, 5 \%$, and $10 \%$ significance level, respectively

${ }^{\mathrm{a}}$ s.e. refers to cluster-corrected standard errors

${ }^{\mathrm{d}}$ Dummy variable

\section{The Role of On-Farm Diversity}

Diversified on-farm agricultural production was significantly associated with higher dietary diversity. We find that increasing production by one more food group is associated with 0.074 food groups consumed. This is obviously low and, it is questionable if this is a valuable strategy for the sample farmers to improve their food and nutrition security. Our findings contrast with the results of Sibhatu et al. (2015), who found an insignificant effect of production diversity for a nationally representative dataset of Ethiopia. Possible explanations for the opposing findings may be the deviating average production diversity or the different measurement approaches (i.e., using the crop count rather than the HPDS9) or both. Food groups of oils and fats, sweets, and spices, condiments and beverages are not produced by farmers, but must be purchased on the market. Therefore, it might be more relevant for rather diversified farms to specialize and shift toward an increased focus on income generation. 
One should also bear in mind the question of how production diversity is achieved. Some management practices like intercropping and agroforestry increase production diversity. In addition, such technologies reduce soil erosion, improve water availability, and support beneficial micro-climates, which all may contribute to ensuring or enhancing yields (Szumigalski and van Acker 2005; Zöbisch et al. 1995). Therefore, reasons for production diversity levels should be considered in future research when analyzing their influence on household dietary diversity, especially regarding climatic stress and seasonality.

\section{The Role of Non-Farm Income}

A positive association was estimated between non-farm income and households' dietary diversity. Engaging in the non-farm activities could be a helpful strategy of farming households to generate higher income, which may be spent to improve their dietary diversity.

To get a clearer understanding of households with and without non-farm activities, key variables are presented in Table 3. Concerning agricultural productivity, Holden et al. (2004) argue that non-farm activities compromise agricultural productivity. The mean farm size is no different between the two groups. The average levels of the lowest food supply in the past 12 months are significantly higher for the group that generated non-farm income. Thus, the assumption by de Janvry et al. (1991) and Kinsey et al. (1998), for example, that non-farm income works as a risk spreading technique and strengthens resilience, can be supported by this study. Households with non-farm incomes are significantly higher educated. The most important nonfarm activities carried out are lucrative employments, like trading (62.1\%), handicraft $(9.2 \%)$, and construction work (7.2\%). This seems to confirm the findings of Woldenhanna and Oskam (2001), that lucrative employment and self-employment opportunities work as pull factors. Moreover, the findings on the difference in education might also hint at the existence of entry barriers, based on education level. At

Table 3 Socio-economic characteristics of households with and without non-farm income

\begin{tabular}{|c|c|c|c|c|}
\hline & Mean & $\begin{array}{l}\text { Mean with non- } \\
\text { farm income }\end{array}$ & $\begin{array}{l}\text { Mean without } \\
\text { non-farm income }\end{array}$ & Difference \\
\hline HDDS & 6.67 & 6.94 & 6.53 & $0.41 * * *$ \\
\hline HPDS9 & 3.74 & 3.80 & 3.71 & 0.09 \\
\hline $\begin{array}{l}\text { Lowest food supply level in the past } \\
12 \text { months (1-very low to } 5 \text {-very high) }\end{array}$ & 2.55 & 2.60 & 2.53 & $0.07 * * *$ \\
\hline Years of education & 3.14 & 4.16 & 2.60 & $1.56 * * *$ \\
\hline Female household head $^{\mathrm{d}}$ & 0.17 & 0.10 & 0.20 & $0.10^{* * *}$ \\
\hline Total farm size (ha) & 1.66 & 1.55 & 1.71 & 0.16 \\
\hline $\mathrm{N}$ & 400 & 137 & 263 & \\
\hline
\end{tabular}

*** denotes $1 \%$ significance level

${ }^{\mathrm{d}}$ Dummy variable 
least for the major income source of trading, a certain education level is assumed to be necessary.

\section{The Role of Market Access}

The average total value of assets owned by households is low and about $20 \%$ of the average gross profit comes from annual crop production. Accordingly, most of the respondents walk to the nearest periodic market to buy commodities or sell their produce. The average travel time is less than $50 \mathrm{~min}$, an estimated $4 \mathrm{~km}$, which is rather short compared with the market distances reported in other studies (e.g., Sibhatu et al. 2015). Such deviations are likely to be the result of lacking a best practice in measuring market access, be it as a dummy variable, the distance to markets or different types of roads, or travel time. Thus, a consensus could help to provide comprehensive and comparable results across different studies. Yet, every study area is characterized by local or regional conditions justifying either approach. Differences in the definition of a market and market access are hence assumed to be primary reasons for finding different effects of market access on household dietary diversity.

Regarding the level of participation in marketing, a higher share of sold crop harvest significantly associates with better dietary diversity indicators. The magnitude of the association indicates that an additional $15 \%$ of the harvest sold links to a higher dietary diversity by one food group in 12 groups specification. This implies that households could improve their food and nutrition security by being more market-oriented. When looking at descriptive differences between more and less market-oriented households (see Table 4), more market-oriented farmers have a higher cash income (gross profit from crop sales), which then can be used to purchase food items that are not or cannot be produced by the household. This also explains the

Table 4 Socio-economic characteristics of households by market orientation

\begin{tabular}{|c|c|c|c|c|}
\hline & Mean & $\begin{array}{l}\text { Share of harvest } \\
\text { sold } \sim 50 \%\end{array}$ & $\begin{array}{l}\text { Share of harvest } \\
\text { sold }>50 \%\end{array}$ & Difference \\
\hline HDDS & 6.67 & 6.41 & 6.88 & $0.47 * * *$ \\
\hline HPDS9 & 23.74 & 3.26 & 4.12 & $0.86^{* * *}$ \\
\hline $\begin{array}{l}\text { Lowest food supply level in the past } \\
12 \text { months (1-very low to 5-very high) }\end{array}$ & 2.55 & 2.5 & 2.6 & 0.1 \\
\hline Years of education & 3.14 & 2.98 & 3.26 & $0.28 * * *$ \\
\hline Total farm size (ha) & 1.66 & 1.62 & 1.69 & 0.07 \\
\hline Time to market (minutes) & 47.59 & 52.94 & 43.36 & $9.56 * * *$ \\
\hline Gross profit from crop sales ('000 ETB) & 26.08 & 9.86 & 38.95 & $29.09 * * *$ \\
\hline Management-based technologies ${ }^{\mathrm{d}}$ & 0.69 & 0.68 & 0.70 & 0.02 \\
\hline Input-based technologies ${ }^{\mathrm{d}}$ & 0.42 & 0.40 & 0.43 & 0.03 \\
\hline$N$ & 400 & 177 & 223 & \\
\hline
\end{tabular}

$* * *$ denotes $1 \%$ significance level

${ }^{\mathrm{d}}$ Dummy variable 
significantly higher dietary diversity. Moreover, those who sell more than half of their agricultural produce seem to spend less time traveling to the markets than the farmers who sell less than half of their farm produce.

Market orientation and production diversity do not seem to contradict one another. On the contrary, the results presented in Table 4 show that households with more than $50 \%$ of their harvest sold at market have significantly higher production diversity. The inherent assumption by different researchers (e.g., de Janvry et al. 1991 and Sibhatu et al. 2015) that an increased production diversity indicates a focus on subsistence production, or vice versa, cannot be supported. Our results rather go in line with findings from Hirvonen and Headey (2018), who report that the adoption of home gardens is more likely when farmers are located near markets in Ethiopia. For Benin, Bellon et al. (2016) also find that on-farm production diversity is linked to better market opportunities.

\section{Summary and Concluding Remarks}

In this paper, we investigated the association of on-farm production diversity, nonfarm income, and market access with household dietary diversity as an indicator of food and nutrition security among Ethiopian smallholder farmers. To identify determining factors and assess their influence on dietary diversity, generalized Poisson regression models of dietary diversity scores of 12 and 9 food groups were estimated. Next to the main variables of interest, different agricultural technology adoption variables and socio-economic characteristics were considered in the analyses.

The information given in this study does not fully reflect the food and nutrition security status of the observed households, which might have caused an over- or underestimation of the same. The dietary diversity indicators of 12 and 9 food group specifications were used as a proxy for the determination of household food and nutrition security and cannot fully account for all aspects of this complex status due to a focus on food access and utilization. It also does not account for the household's nor its individual members' nutrient adequacy, consumption quantity, or intra-household distribution. Extrapolation to the rest of the year or Ethiopia as a whole is not possible, due to issues of seasonality and the non-representative characteristics of the underlying database. The areas that were considered in this study are assumed to be the most important as almost all respondents engaged in agricultural production and income generation and they are key to food and nutrition security in smallholder farming households. Livestock production was not portrayed in the study in detail; however, it seems to be a relevant income source that should be examined in more detail alongside on-farm and income diversification decisions in future research. Meals eaten outside the house could not be included in this analysis, based on the missing data of this part of the questionnaire. It is, however, assumed that the nutritional values and expenditures of those meals are negligible, given the context of relatively poor smallholder farming households in Ethiopia.

We find that on-farm production diversification significantly associates with dietary diversity indicators. This finding is especially important for those households growing few crops and that are poor in asset ownership. The magnitudes of 
the estimated associations are however low. In terms of on-farm related factors, the adoption of input-based technologies seems to matter too. This differing influence of production diversity indicates that policy interventions targeting food and nutrition security should consider the heterogeneity of farming practices regarding the overlapping occurrence of production diversity for subsistence-consumption and income generation in Ethiopia.

The expected positive association of non-farm income with household dietary diversity was confirmed. Non-farm income is in this sense more a tool for risk reduction and compensation for small farm sizes, rather than a main pillar for income generation. In contrast to the findings of Holden et al. (2004), non-farm activities do not compromise agricultural productivity. Challenging, however, are possibly the limited non-farm income opportunities in rural areas. These findings imply that policy strategies aiming at fostering the development of nonfarm jobs are likely to improve rural livelihoods and food and nutrition security. Keeping in mind the aging rural farming population, supporting agribusinesses and thereby creating job opportunities, may contribute to slowing the migration of rural youth. Increasing economic development and the shift in the political agenda toward strengthening the industrial and service sector, suggest that future research should emphasize the role of non-agricultural income sources not only to increase the income of farming households, but also to cope with an expected change in land ownership, labor requirements, and agricultural management due to an agricultural industrialization. Therefore, this study emphasizes the role of non-farm activities as a source of additional income for the provision of a more stable food situation in the regularly drought-stricken Ethiopia.

Improved market access and participation are found to positively influence household dietary diversity. We find that the marginal effect of market access is rather low. We suggest that considering the time aspect is more appropriate in rural settings. Regarding the market aspect, the degree of market participation, that is, the share of crop harvest sold, positively associates with dietary diversity. This finding underlines the relevance of income generation for households to purchase food commodities, particularly those items that are not home-produced or available throughout the year.

In contrast with other studies that found that increased production diversification is a reaction to market failures and subsistence orientation, our results show that more market-oriented farmers have more on-farm diversity in the underlying sample. As market distance and baseline production diversity differ between the samples, we conclude that such infrastructural factors should be carefully considered when interpreting research results and drawing policy implications. It appears to be important that policy makers and other non-governmental stakeholders recognize that production diversity and increased market participation are not mutually exclusive but should be assessed on a case-by-case basis.

Acknowledgements This research was financially supported by the German Research Foundation (DFG) under the grant number ZE 502/1-1 and 602066.

Funding Open Access funding enabled and organized by Projekt DEAL. 


\section{Declarations}

Conflict of interest The authors declare that they have no conflict of interest.

Open Access This article is licensed under a Creative Commons Attribution 4.0 International License, which permits use, sharing, adaptation, distribution and reproduction in any medium or format, as long as you give appropriate credit to the original author(s) and the source, provide a link to the Creative Commons licence, and indicate if changes were made. The images or other third party material in this article are included in the article's Creative Commons licence, unless indicated otherwise in a credit line to the material. If material is not included in the article's Creative Commons licence and your intended use is not permitted by statutory regulation or exceeds the permitted use, you will need to obtain permission directly from the copyright holder. To view a copy of this licence, visit http://creativecommons.org/licen ses/by/4.0/.

\section{References}

Bachewe, F.N., Berhane, G., Minten, B., and Taffesse, A.S. 2015. Agricultural growth in Ethiopia (2004-2014): evidence and drivers. ESSP II Working Paper 81. Washington, DC: International Food Policy Research Institute (IFPRI).

Barrett, C.B. 2010. Food systems and the escape from poverty and ill-health traps in Sub-Saharan Africa. Ithaca, NY: Cornell University Press.

Barrett, C.B., T. Reardon, and P. Webb. 2001. Nonfarm income diversification and household livelihood strategies in rural Africa: Concepts, dynamics, and policy implications. Food Policy. https://doi.org/10.1016/S0306-9192(01)00014-8.

Bellon, M.R., G.D. Ntandou-Bouzitou, and F. Caracciolo. 2016. On-farm diversity and market participation are positively associated with dietary diversity of rural mothers in Southern Benin West Africa. PLOS ONE. https://doi.org/10.1371/journal.pone.0162535.

Berhane, G., Hoddinott, J., Kumar, N., Taffesse, A.S., Diressie, M.T., Yohannes, Y., Sabates-Wheeler, R., Handino, M., Lind, J., Tefera, M. and Sima, F. 2013. Evaluation of Ethiopia's food security program: Documenting progress in the implementation of the productive safety nets programme and the household asset building programme. ESSP II-EDRI Report. Washington, DC: International Food Policy Research Institute (IFPRI), University of Sussex, Dadimos.

Berti, P.R. 2015. Relationship between production diversity and dietary diversity depends on how number of foods is counted. PNAS. https://doi.org/10.1073/pnas.1517006112.

Consul, P.C. 1989. Generalized Poisson distribution: Properties and applications, vol. 99. New York, USA: CRC Press.

Consul, P.C., and G.C. Jain. 1973. A generalization of the Poisson distribution. Technometrics 15 (4): 791-799.

De Janvry, A., M. Fafchamps, and E. Sadoulet. 1991. Peasant household behaviour with missing markets: Some paradoxes explained. The Economic Journal 101 (409): 1400-1417.

Emana, B., Gebremedhin, H., and Regassa, N. 2010. Impacts of improved seeds and agrochemicals on food security and environment in the rift valley of Ethiopia: implications for the application of an African green revolution. DCG Report, 56. Oslo, Norway: Drylands Coordination Group.

FAO. 2014. Ethiopia country programming framework 2012-2015. Revised Document September 2014. Addis Ababa, Ethiopia: Food and Agriculture Organization of the United Nations,

Gillespie, S., and M. van den Bold. 2017. Agriculture, food systems, and nutrition: Meeting the challenge. Global Challenges. https://doi.org/10.1002/gch2.201600002.

Greene, W.H. 2012. Econometric analysis, vol. 7. Boston: Pearson Higher Edcuation.

Harris, T., Z. Yang, and J.W. Hardin. 2012. Modeling underdispersed count data with generalized Poisson regression. The Stata Journal 12 (4): 736-748.

Hatløy, A., L. Torheim, and A. Oshaug. 1998. Food variety: A good indicator of nutritional adequacy of the diet? A case study from an urban area in Mali, West Africa. European Journal of Clinical Nutrition 52: 891-898. 
Hirvonen, K., and D. Headey. 2018. Can governments promote homestead gardening at scale? Evidence from Ethiopia. Global Food Security. https://doi.org/10.1016/j.gfs.2018.09.001.

Hirvonen, K., and Hoddinott, J. 2014. Agricultural Production and Children's Diets: Evidence from Rural Ethiopia. Ethiopia Strategy Support Program, Working Paper 69.

Hirvonen, K., Taffesse, A.S., and Hassen, I.W. 2015. Seasonality and household diets in Ethiopia. Ethiopia Strategy Support Program, Working Paper 74.

Headey, D., and O. Ecker. 2013. Rethinking the measurement of food security: From first principles to best practice. Food Security. https://doi.org/10.1007/s12571-013-0253-0.

Holden, S., B. Shiferaw, and J. Pender. 2004. Non-farm income, household welfare, and sustainable land management in a less-favoured area in the Ethiopian highlands. Food Policy 29 (4): 369-392.

Jones, A.D., F.M. Ngure, G. Pelto, and S.L. Young. 2013. What are we assessing when we measure food security? A compendium and review of current metrics. Advances in Nutrition. https://doi. org/10.3945/an.113.004119.

Jones, A.D., A. Shrinivas, and R. Bezner-Kerr. 2014. Farm production diversity is associated with greater household dietary diversity in Malawi: Findings from nationally representative data. Food Policy. https://doi.org/10.1016/j.foodpol.2014.02.001.

Kant, A.K. 2004. Dietary patterns and health outcomes. Journal of the American Dietetic Association. https://doi.org/10.1016/j.jada.2004.01.010.

Kennedy, G., T. Ballard, and M.C. Dop. 2010. Guidelines for measuring household and individual dietary diversity. Rome Italy: Food and Agriculture Organization of the United Nations.

Kinsey, B., K. Burger, and J.W. Gunning. 1998. Coping with drought in Zimbabwe: Survey evidence on responses of rural households to risk. World Development 26 (1): 89-110.

Koppmair, S., M. Kassie, and M. Qaim. 2017. Farm production, market access and dietary diversity in Malawi. Public Health Nutrition. https://doi.org/10.1017/S1368980016002135.

Minten, B., B. Koru, and D. Stifel. 2013. The last mile(s) in modern input distribution: Pricing, profitability, and adoption. Agricultural Economics. https://doi.org/10.1111/agec.12078.

Muller, C. 2009. Do agricultural outputs of partly autarkic peasants affect their health and nutrition? Evidence from Rwanda. Food Policy. https://doi.org/10.1016/j.foodpol.2008.10.010.

O'Brien, R.M. 2007. A caution regarding rules of thumb for variance inflation factors. Quality and Quantity. https://doi.org/10.1007/s11135-006-9018-6.

Otsuka, K., and T. Yamano. 2006. Introduction to the special issue on the role of nonfarm income in poverty reduction: Evidence from Asia and East Africa. Agricultural Economics. https://doi.org/ 10.1111/j.1574-0862.2006.00185.x.

Reardon, T., E. Crawford, and V. Kelly. 1994. Links between nonfarm income and farm investment in African households: Adding the capital market perspective. American Journal of Agricultural Economics 76 (5): 1172-1176.

Rose, D., S. Meershoek, C. Ismael, and M. McEwan. 2002. Evaluation of a rapid field tool for assessing household diet quality in Mozambique. Food and Nutrition Bulletin. https://doi.org/10.1177/ 156482650202300207.

Ruel, M.T. 2003. Operationalizing dietary diversity: A review of measurement issues and research priorities. The Journal of Nutrition. https://doi.org/10.1093/jn/133.11.3911S.

Sariyev, O., T.K. Loos, and L.Y. Khor. 2021. Intra-household decision-making production diversity and dietary quality: a panel data analysis of Ethiopian rural households. Food Security 13 (1): 181-197. https://doi.org/10.1007/s12571-020-01098-9

Sibhatu, K.T., V.V. Krishna, and M. Qaim. 2015. Production diversity and dietary diversity in smallholder farm households. PNAS. https://doi.org/10.1073/pnas.1510982112.

Sibhatu, K.T., and M. Qaim. 2018a. Farm production diversity and dietary quality: Linkages and measurement issues. Food Security. https://doi.org/10.1007/s12571-017-0762-3.

Sibhatu, K.T., and M. Qaim. 2018b. Review: Meta-analysis of the association between production diversity, diets, and nutrition in smallholder farm households. Food Policy. https://doi.org/10. 1016/j.foodpol.2018.04.013.

Snapp, S.S., and M. Fisher. 2014. "Filling the maize basket" supports crop diversity and quality of household diet in Malawi. Food Security. https://doi.org/10.1007/s12571-014-0410-0.

Stifel, D., and B. Minten. 2017. Market access, well-being, and nutrition: Evidence from Ethiopia. World Development 90: 229-241.

Szumigalski, A., and R. Van Acker. 2005. Weed suppression and crop production in annual intercrops. Weed Science. https://doi.org/10.1614/WS-05-014R.1. 
Tarini, A., S. Bakari, and H. Delisle. 1999. The overall nutritional quality of the diet is reflected in the growth of Nigerian children. Santé 9 (1): 23-31.

Torheim, L.E., F. Ouattara, M.M. Diarra, F.D. Thiam, I. Barikmo, A. Hatløy, and A. Oshaug. 2004. Nutrient adequacy and dietary diversity in rural Mali: Association and determinants. European Journal of Clinical Nutrition. https://doi.org/10.1038/sj.ejen.1601853.

UNDP. 2016. Human development for everyone: Briefing note for countries on the 2016. United Nations Development Programme, Human Development Report. New York: UNDP.

Winkelmann, R., and K.F. Zimmermann. 1994. Count data models for demographic data. Mathematical Population Studies 4 (3): 205-221.

World Bank. 2016. Ethiopia: Priorities for ending extreme poverty and promoting shared prosperity. World Bank, Report No. 100592-ET.

World Food Programme. 2014. Nutrition sensitive programming: What and why? West African. Nutrition Bulletin 1: 25.

Zöbisch, M., C. Richter, B. Heiligtag, and R. Schlott. 1995. Nutrient losses from cropland in the Central Highlands of Kenya due to surface runoff and soil erosion. Soil and Tillage Research. https://doi. org/10.1016/0167-1987(94)00441-G.

Publisher's Note Springer Nature remains neutral with regard to jurisdictional claims in published maps and institutional affiliations. 